\title{
2012-03-07
}

\section{Demystifying Computing with Magic, continued}

DAN GARCIA UC Berkeley

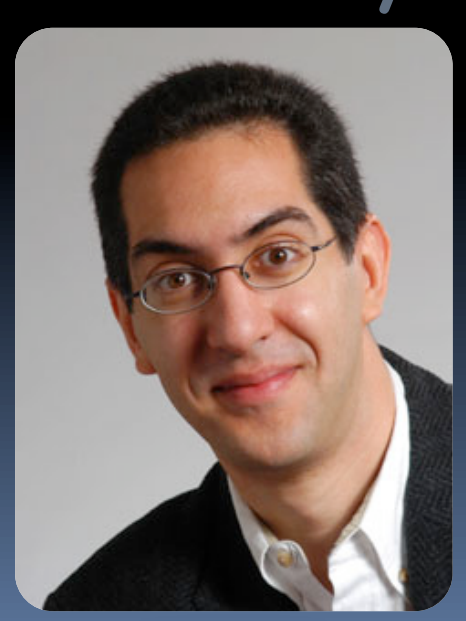

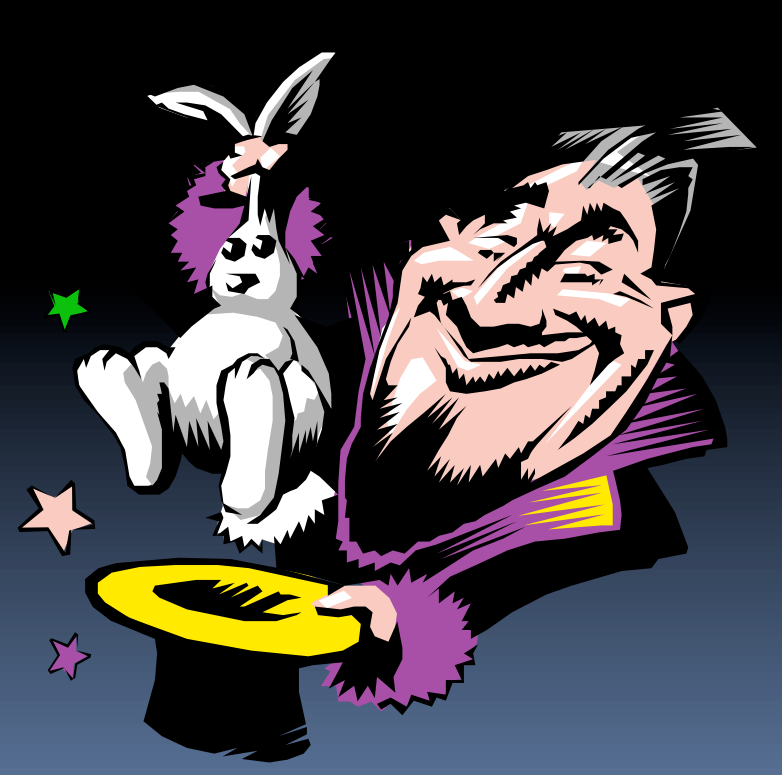

DAVID GINAT Tel-Aviv University

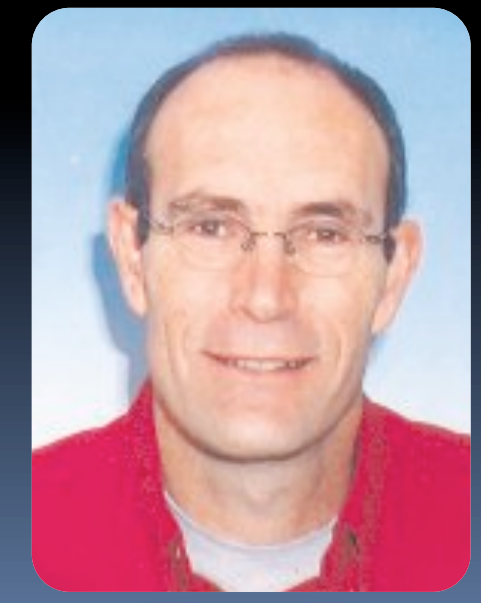




\section{Special Session Overview}

- Motivation

- The 7 magic tricks

- Real-Time 4×4 Magic Square

- Left/Right Game

- The Tricky Dice

- The Numbers Game

- Find the Card

- Guess Your Age

- Guess Your Birthday Day of Week

- Reflection

- Other References

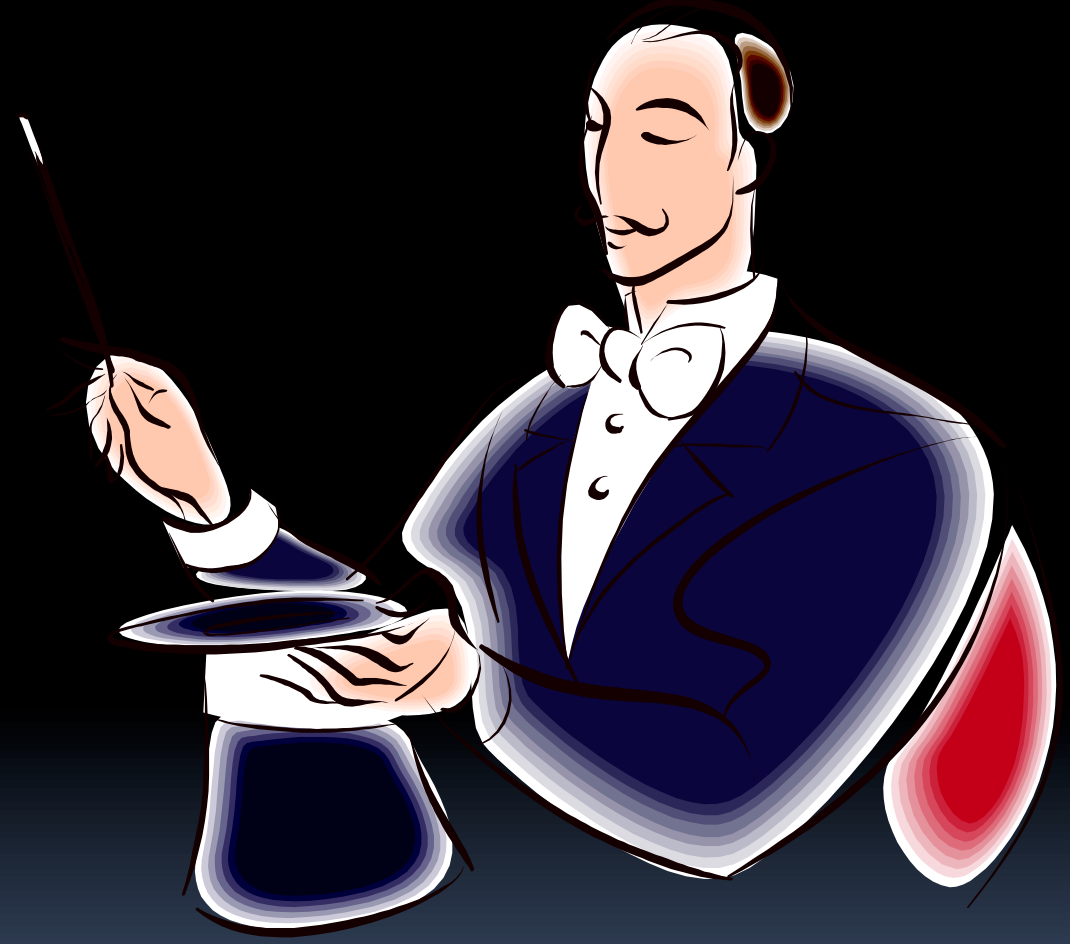

- YOU contribute your tricks 
Magic

is Fun! 


\section{but Magic}

\section{can be much more than fun!}




\section{Magic can Motivate, Illustrate, Elaborate...}

- Computing notions

- Discrete math terms: e.g., permutations,

- Problem representation: e.g., binary digits

- Algorithmic patterns: e.g., sorting

- General notions: e.g., symmetry

- Problem solving

- Problem decomposition

- Simplification, Generalization

- Backward reasoning

- Analogy (transfer)

- Problem representation 


\section{Real-Time $4 \times 4$ Magic Square}

- Volunteer is asked for a number $N$ from 25-100

- You create a magic square, where the sum of each row, column and diagonal is $\mathbf{N}$

- Source:

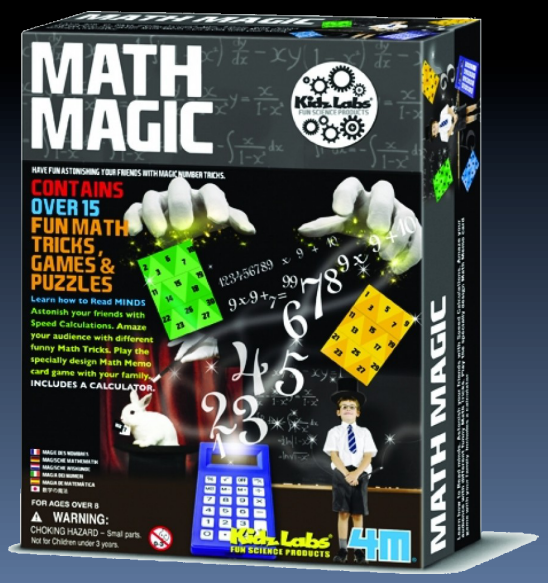

All add to... $\mathbf{N}$
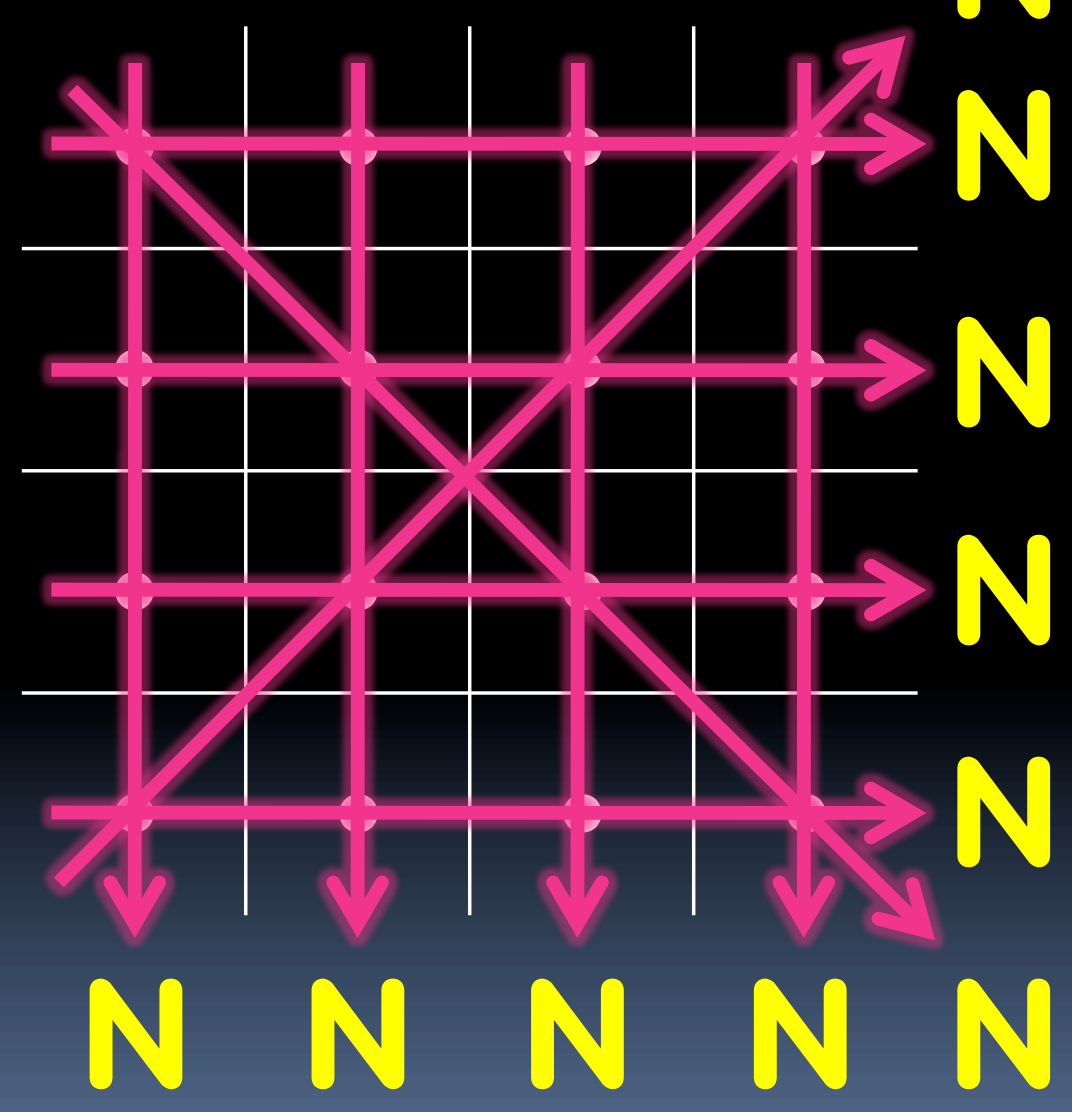

Demystifying Computing with Mogic, continued 


\section{How it Works; What Students Learn}

- Mechanics

- Make-Magic-Square(N)

- Have a grid with the value already written faintly (or memorize it)

- What they learn

- Value of lookup table

- Correctness proof

- Decomposition

- Algebraic representation

- Value of randomness

- 8 rotations-and-flips

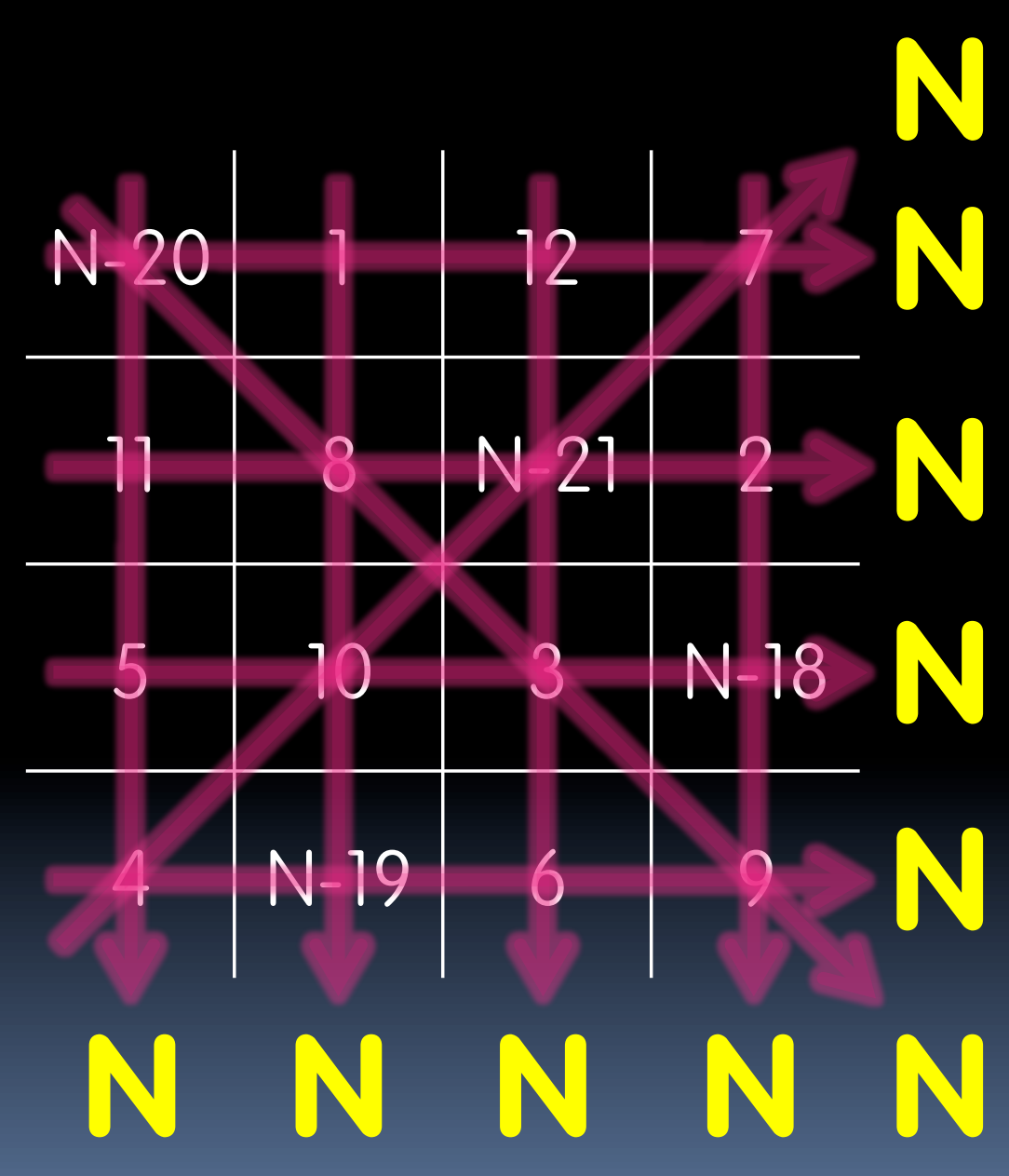




\section{LEFT/RIGHT CARD GAME [10/96]}

A line of $2 \mathrm{~N}$ integer cards

Two players, alternating turns

Each player, on her turn, takes a card from one of the line ends (left or right)

The winner is the player whose sum of $\mathrm{N}$ cards is larger 


\section{THE MAGIC}

A volunteer from the audience arranges the line of

$2 n$ cards as she wishes

The magician looks at the line for a few seconds;

then turns his back to the cards

The player plays against the magician, while the magician does not see the line of cards

The magician is the $7^{\text {st }}$ player, never loses 


\section{A GREEDY HEURISTIC}

$598 \begin{aligned} & 9 \\ & 9\end{aligned}$

Take the larger end

But, maybe the larger end yields

a good move for the opponent? 


\section{ANOTHER GREEDY HEURISTIC}

$\begin{array}{llllllllllll}5 & 9 & 8 & 4 & 7 & 5 & 1 & 2 & 9 & 6 & 3 & 3\end{array}$

Take the card from the end with the better "delta"

\section{But, is it sufficient to look locally?}




\section{EXTREME-VALUES HEURISTIC}

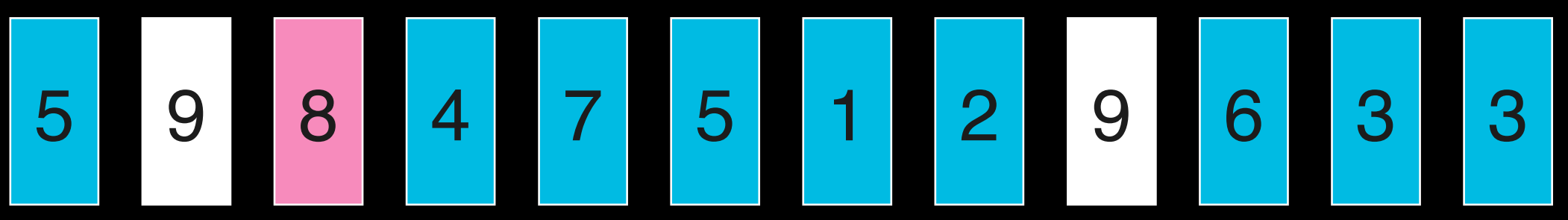

Identify the locations of the larger cards, and try to get these cards

But, how to guarantee getting them? 


\section{DYNAMIC PROGRAMMING}

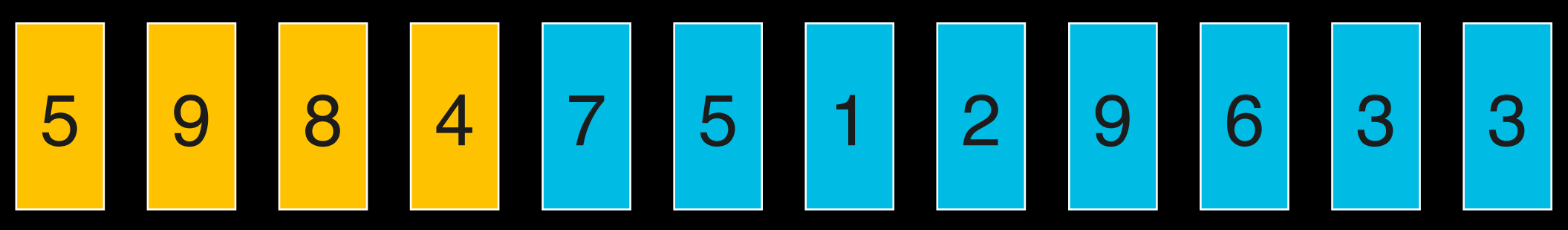

Not simple to program

Requires $\mathrm{O}\left(\mathrm{N}^{2}\right)$ time, $\mathrm{O}(\mathrm{N})$ space (or even $\mathrm{O}\left(\mathrm{N}^{2}\right)$ space, if not experienced) 


\section{SEEK A PATTERN}

598475129633

Employ divergent thinking / creativity

The game involves selection from alternative locations; so maybe look, for a moment, only on locations and not on values 


\section{IDENTIFY A PATTERN}

598475129633

The leftmost card is initially in an odd location and the rightmost card - in an even location

If the leftmost card is removed, then the two ends will be initially-even locations (2 ${ }^{\text {nd }}, 12^{\text {th }}$ ) 


\section{EXTEND THE PATTERN}

$$
59847512963
$$

If the leftmost card is removed, then the two ends will be initially-even location ( $2^{\text {nd }}, 12^{\text {th }}$ )

If the rightmost card is removed, then the two ends will be initially-odd location ( $7^{\text {st }}, 17^{\text {th }}$ ) 


\section{CAPITALIZE ON THE PATTERN}

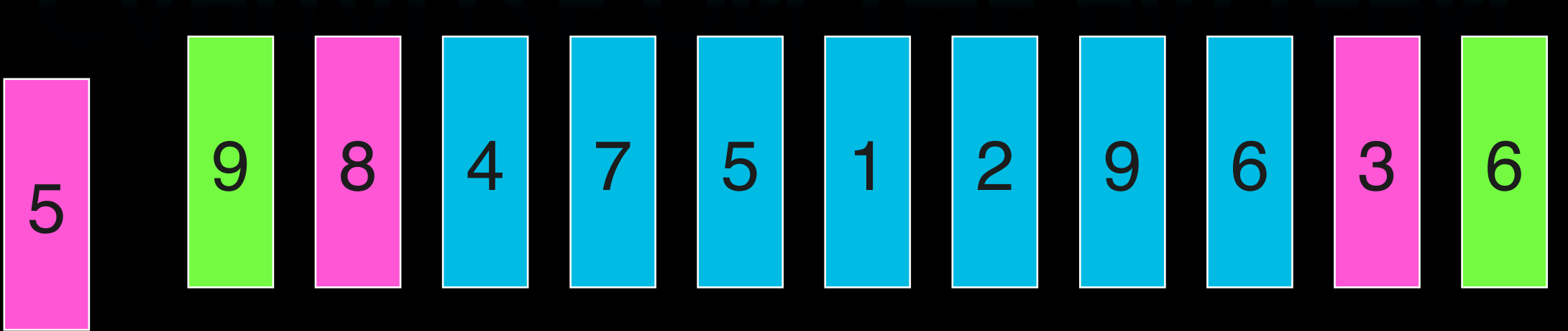

After I remove the card from the $1^{\text {st }}$ location, both ends will be the $2^{\text {nd }}$ and $12^{\text {th }}$ locations; affer my opponent will remove a card, there will again be an end of an initially-odd location; I may remove it, and again leave ends of initially-even locations 
A GAME SCENARIO

$\begin{array}{llllllllllll}5 & 9 & 8 & 4 & 7 & 5 & 1 & 2 & 9 & 6 & 3 & 6\end{array}$

$\begin{array}{llllllllllll}9 & 8 & 4 & 7 & 5 & 1 & 2 & 9 & 6 & 3 & 6\end{array}$

$\begin{array}{lllllllllll}3 & 9 & 8 & 4 & 7 & 5 & 1 & 2 & 9 & 6\end{array}$

$\begin{array}{llllllllll}8 & 4 & 7 & 5 & 1 & 2 & 9 & 6\end{array}$

9 


\section{GAME INVARIANT}

$\begin{array}{lllllllllllll}5 & 9 & 8 & 4 & 7 & 5 & 1 & 2 & 9 & 6 & 3 & 6\end{array}$

Following the above, I may play as follows: "after each of my turns, both ends will be initially-even locations" ${ }^{\prime \prime}$ or:

"affer each of my turns both ends will be initially-odd locations" 


\section{GAME STRATEGY}

$\begin{array}{llllllllllllll}5 & 9 & 8 & 4 & 7 & 5 & 1 & 2 & 9 & 6 & 3 & 6\end{array}$

Sum separately the values in the even locations (here - 32) and the values in the odd locations (here -33 ).

Then, start with the end of the higher sum, and just "imitate" the opponent's moves 


\section{LESSON LEARNED}

Greedy algorithms (be careful ...)

Dynamic programming

Invariance

Values vs locations (addresses)

Divergent thinking 


\section{The Tricky Dice}

- Participant puts dice in a glass

- Magician guesses the numbers on the bottom

- Source: Math Magic
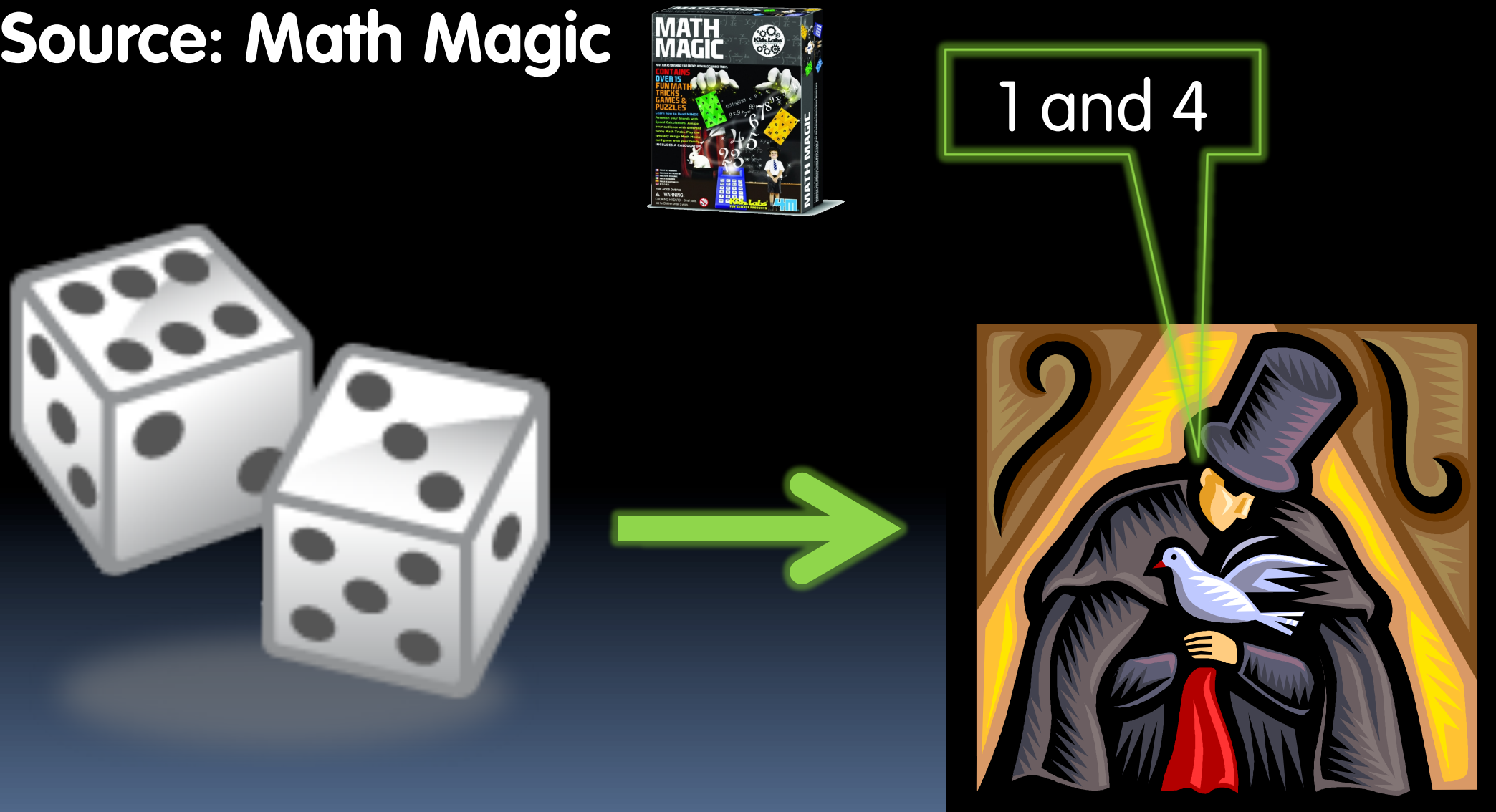


\section{How it Works; What Students Learn}

\section{Mirror}

- Mechanics

- Opposite die sides sum to 7

- Answer is (7-die, $7-$ die $\left._{2}\right)$

- Students Learn

- Good design (in how the pips on a die are chosen)

- Simple algorithm

- Complements
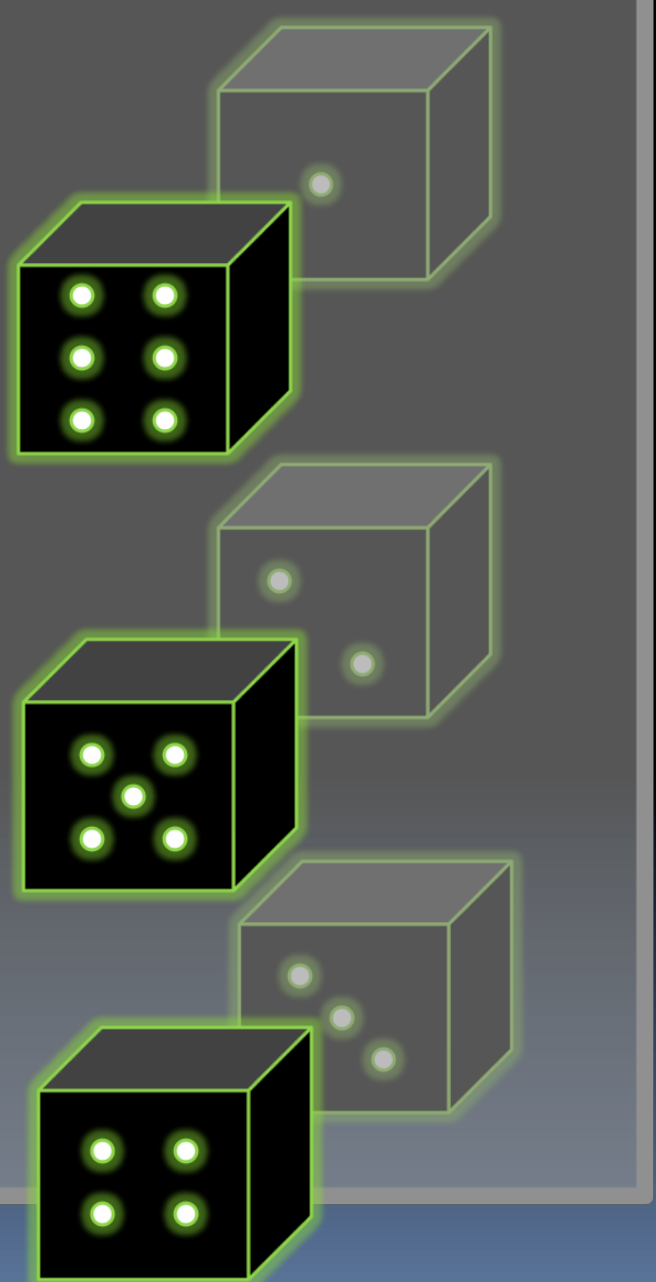


\section{The Numbers Game}

- Participant calls out 10 numbers

- Magician writes numbers on paper, turns them over

- Participant picks random one, magician guesses number

- Source: CS4FN www.cs4fn.org/magic/numbersgame.php

$$
\begin{gathered}
49,124,5,6,8, \\
19,233,69,1,99
\end{gathered}
$$
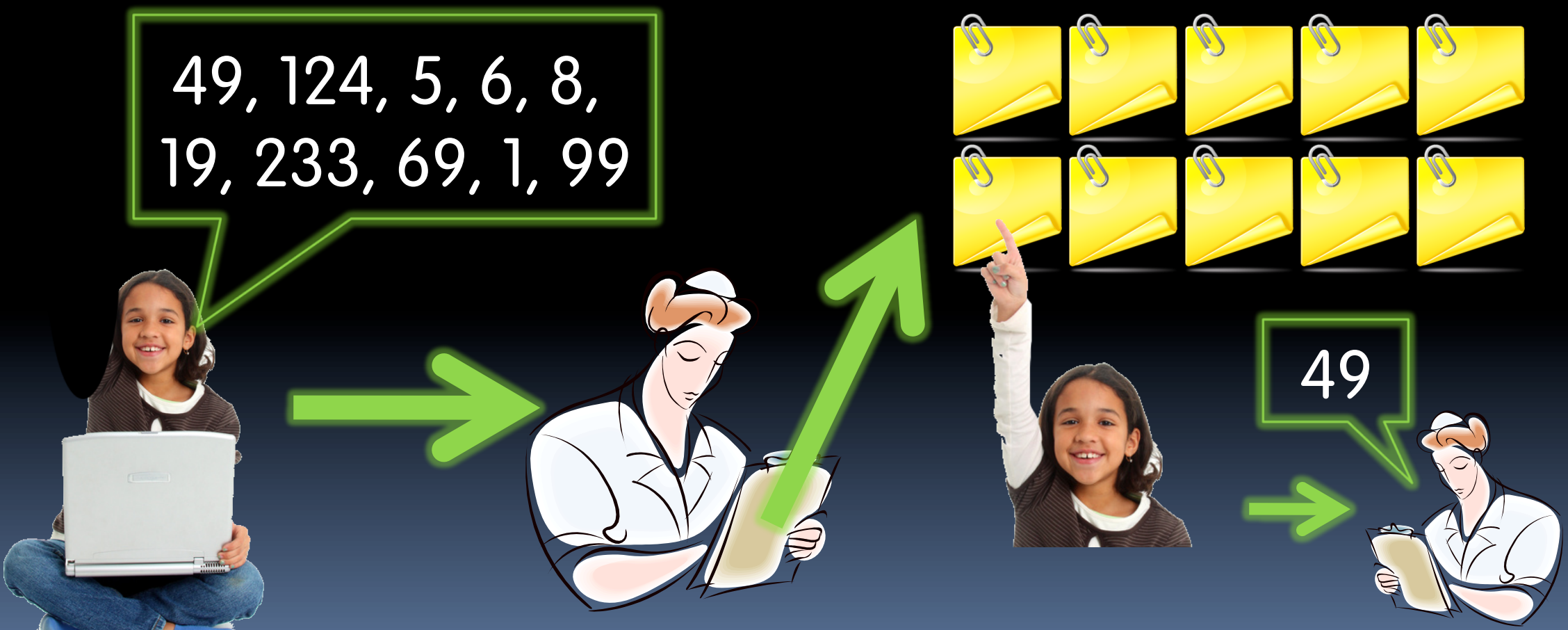


\section{How it Works; What Students Learn}

- Mechanics

- Write $7^{\text {st }}$ number on all cards.

- You never promised anything more than that!

- Students Learn

- $\mathrm{HCl}$ design principle

- You developed a mental model

- That wasn't how things worked

- It's important to make the critical parts of the internal system visible to the user so they see what state it's in.

$$
\begin{aligned}
& 49,124,5,6,8, \\
& 19,233,69,1,99
\end{aligned}
$$

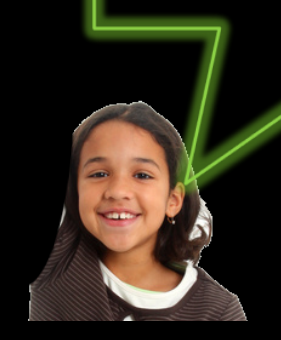




\section{FIND THE CARD}

A volunteer from the audience arranges the cards 1..N in some permutation

Magician-1 looks at the line for a few seconds; leaves it as is, or swaps two cards

Magician-2 enters the room, and the audience calls out any of the integer 1..N

Magician-2 finds the called integer in at most N/2 atfempts 


\section{DIVERGENT THINKING}

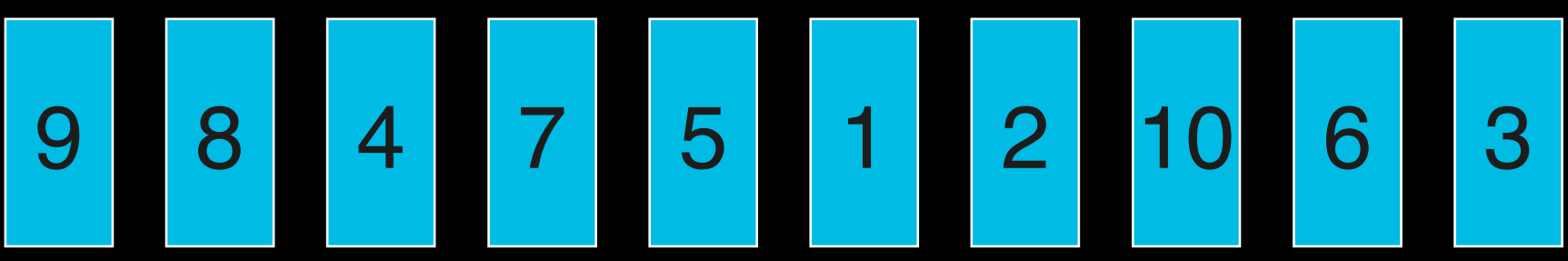

Each value is in the range of the card locations; look at values as pointers (?)

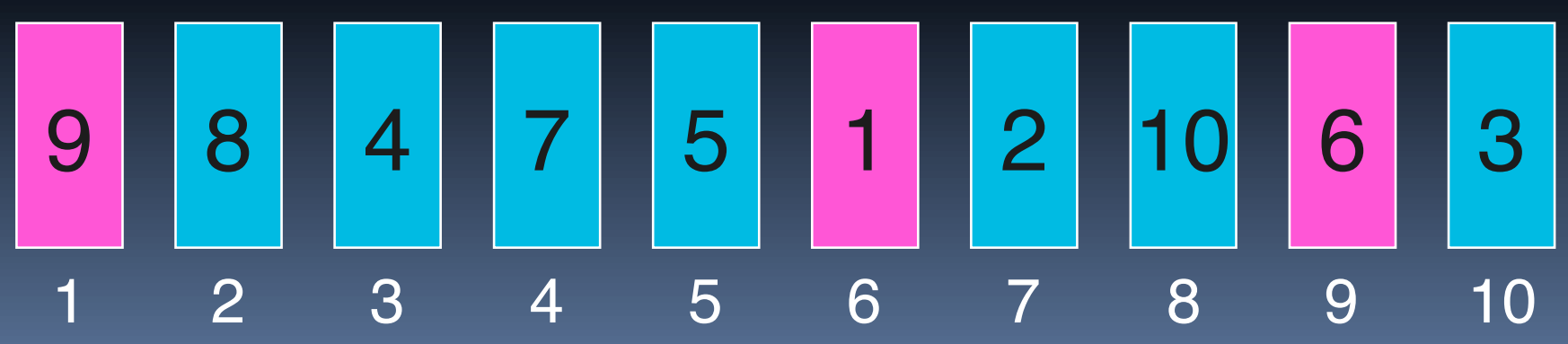




\section{CYCLES OF POINTERS}

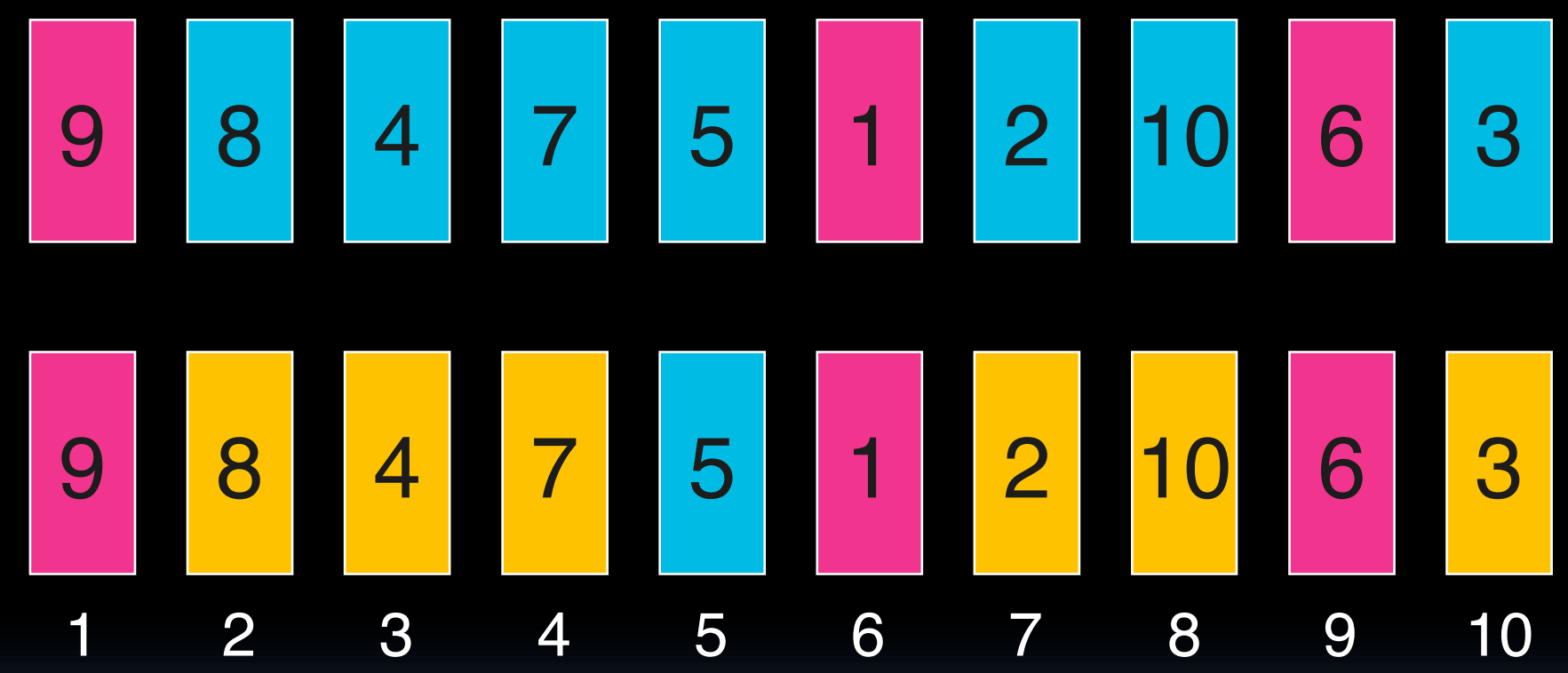

Each card points-at exactly one other card, and is pointed-by one other card 


\section{EACH CARD IN ONE CYCLE}

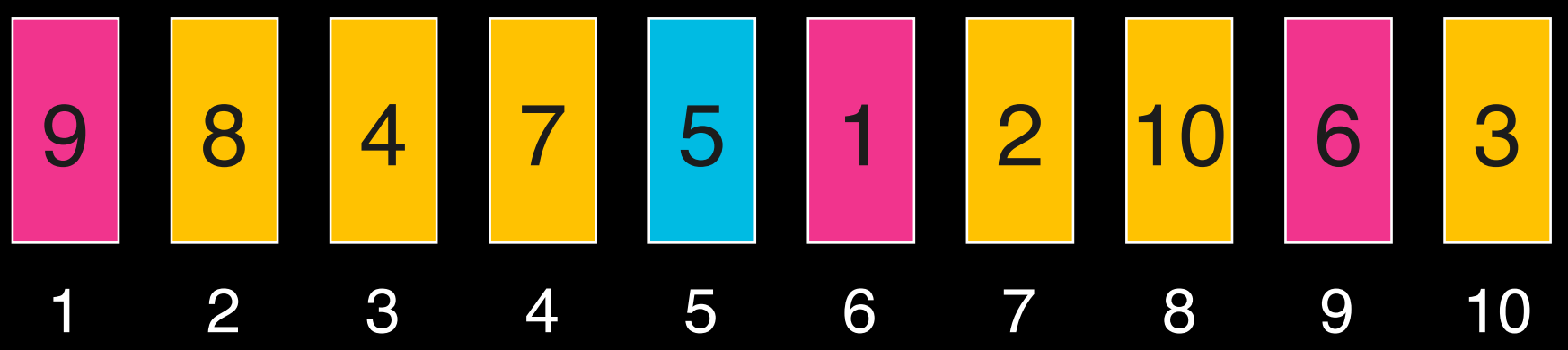

Each card is in exactly one cycle;

the card in the $i^{\text {th }}$ location is in a cycle with the card whose value is $i$, which is it's predecessor in the cycle 


\section{FOLLOW THE CYCLE OF CARD i}

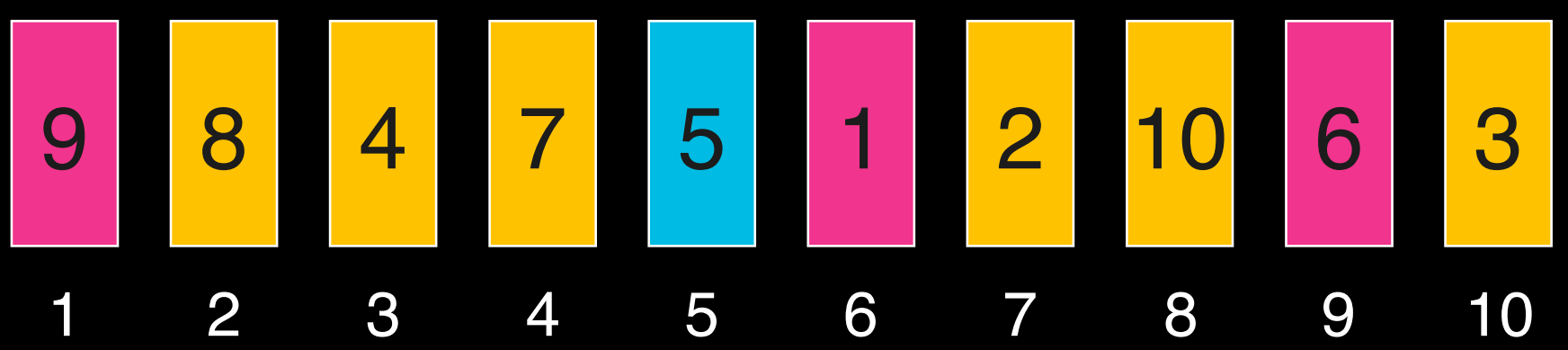

Thus, we may reach the card with value $i$, by following the pointers starting from the $i^{\text {th }}$ card; the amount of work will be the length of the cycle that we follow 


\section{AT MOST ONE LONG CYCLE}

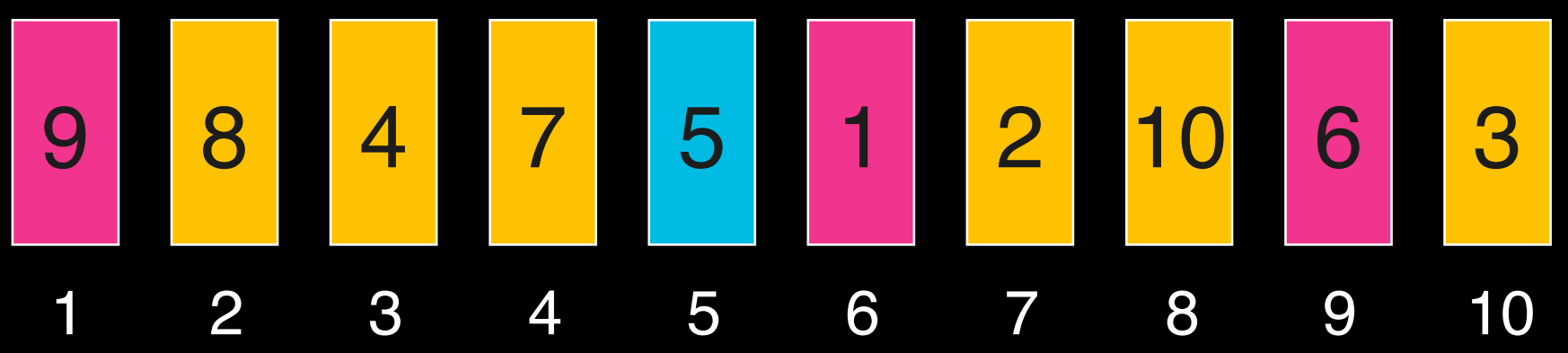

There may be at most one cycle of length larger than N/2; if such a cycle exists, then we may break it into two cycles, by swapping two of its pointers 


\section{BREAK ONE CYCLE INTO TWO}

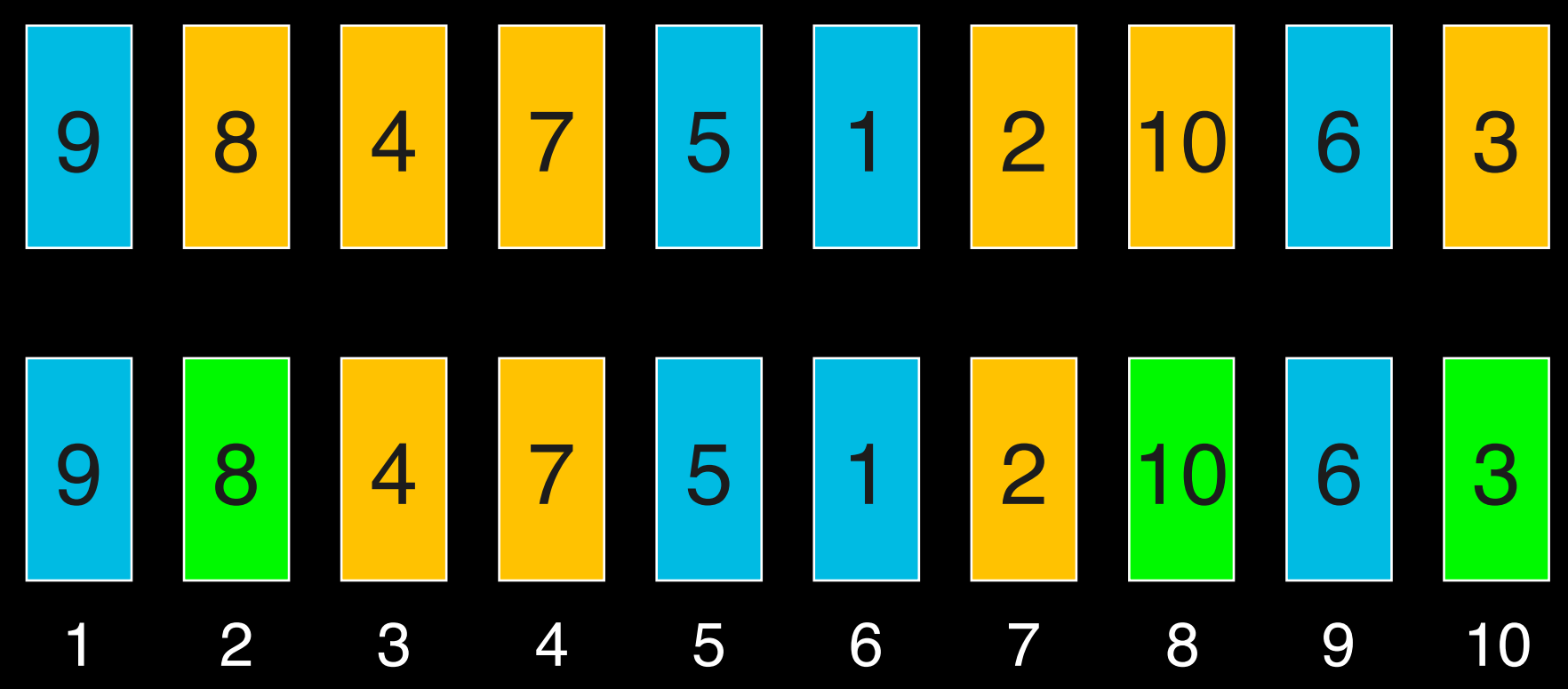

Swap the cycle's middle with its start

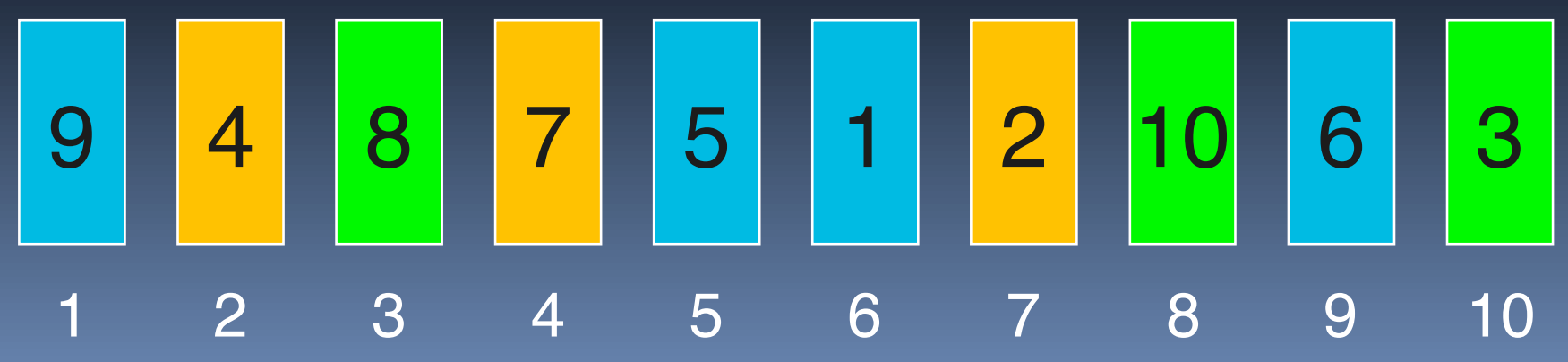




\section{BOUND MAX CYCLE LENGTH}

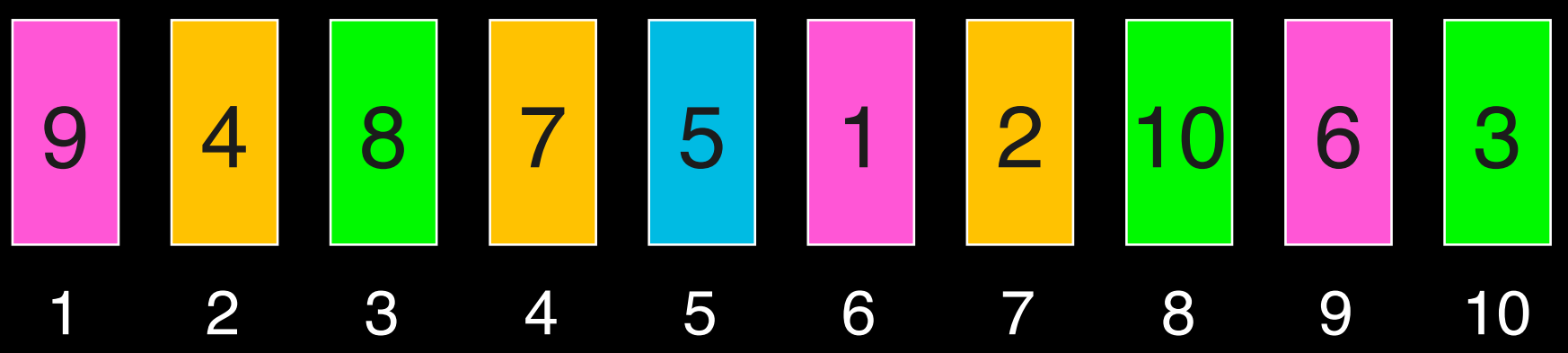

So, if there is a cycle of length larger than N/2, break it after at most N/2 hops into two smaller cycles; each of the cycles will not exceed the length of $N / 2$ 


\section{LESSON LEARNED}

Values as locations (pointers)

Cycles of values in a permutation

A cycle may be broken into two cycles by swapping the locations of two of its pointers 


\section{Guess Your Age}

- Volunteer is handed several cards with "random" numbers written on them

- Returns the cards with age listed on them

- Magician glances and says the person's age

- Source: Math Magic
A 89101112131415
B 456712131415
C 236710111415
D 13579117315
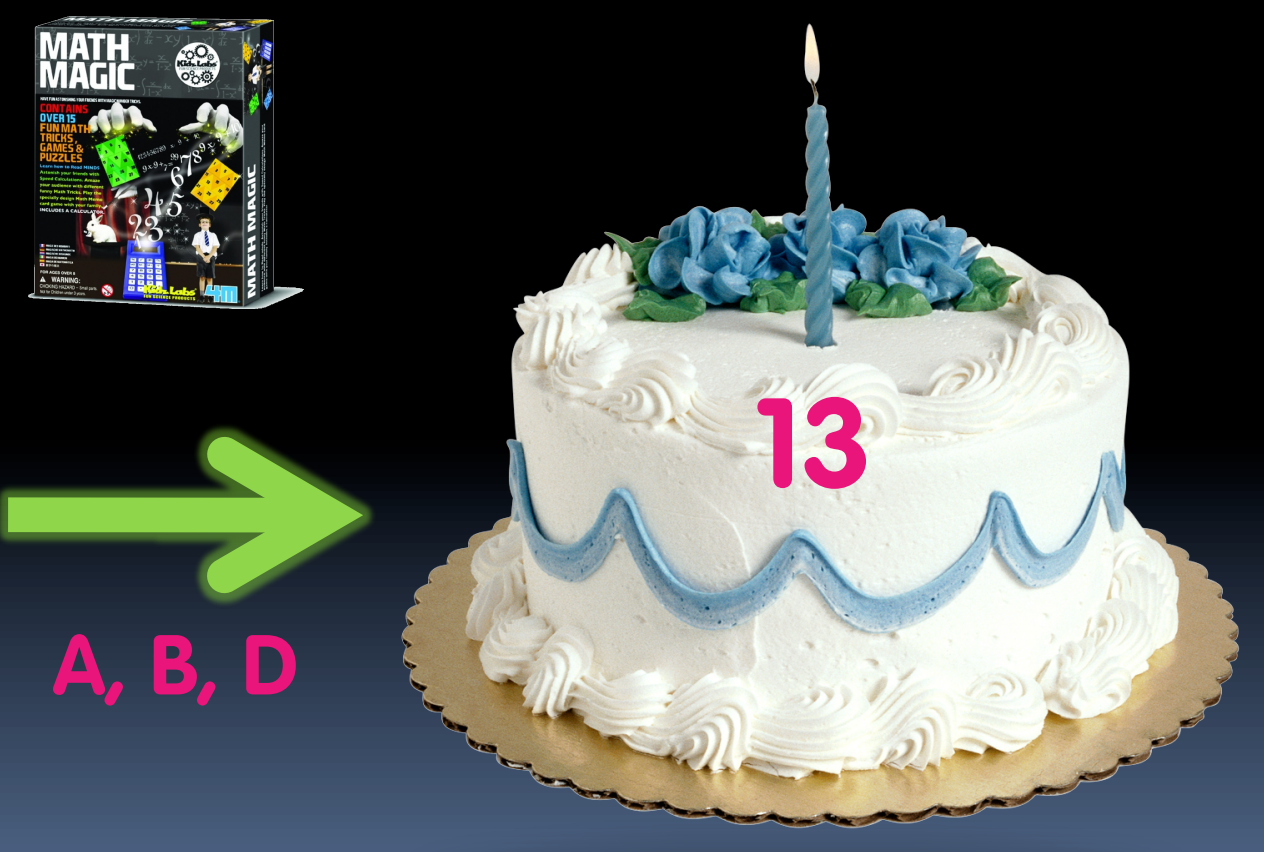


\section{How it Works; What Students Learn}

- Mechanics

- Every card is a column in the binary table

- E.g., " 2 ' $=2$ card has $\{2,3,6,7,10,11,14,15\}$

- The first number in the list is the number of the card.

- Just add those together

- Students Learn

- Intro to Algorithms

- Binary numbers

- Encoding

- Lookup table for quick calc! 


\section{Guess the birthday day of the week}

- Volunteer is asked for their birthday

- Magician says what day of the week it was

- Source: en.wikipedia.org/wiki/Zeller:27s_congruence

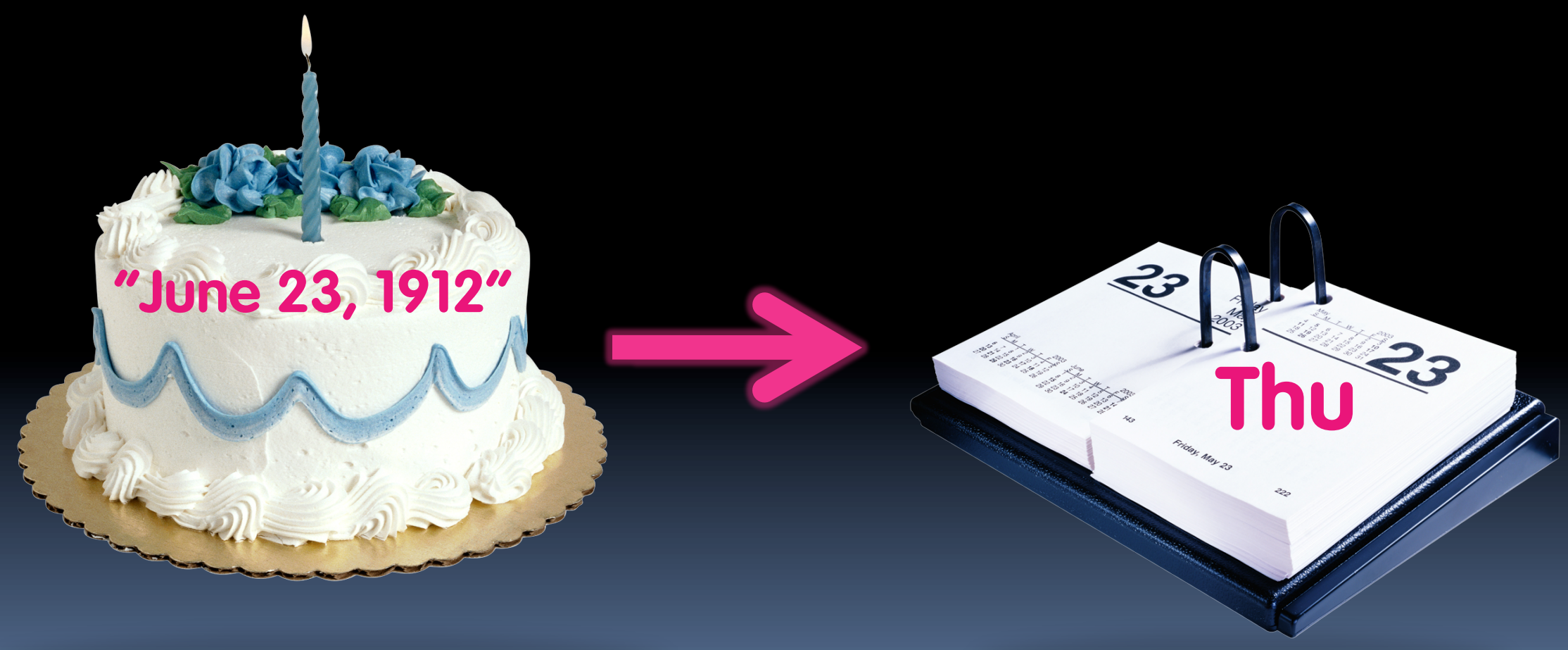




\section{How it Works}

- What they learn: Don't nec generalize

- Alg, value of lookup table, modulo

- Mechanics

- Complicated general alg:

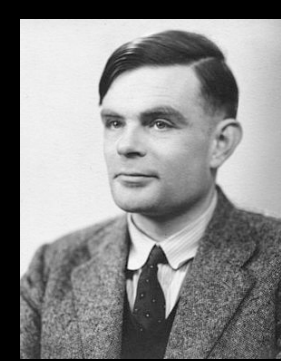

Easier: M, D, Y in 1900s

- Turing: June 23, 1912 (6/23/12)

- Sunday!

- Algorithm

- If $M=1$ or $2, Y=Y-1$

\begin{tabular}{|c|c|c|}
\hline & Y/4\%7 & $(F(M)+D+Y+Y / 4) \% 7$ \\
\hline 0 & 0 & l-index l=Mon $2=$ Tue etc \\
\hline 20 & 5 & \\
\hline 40 & 3 & - Y/4 Tast by Zus: $0,5,3,1,-1$ \\
\hline 60 & 10 & Example \\
\hline 80 & -1 & - $(4+23+12+3) \% 7$ \\
\hline
\end{tabular}

$$
h=\left(q+\left\lfloor\frac{13(m+1)}{5}\right\rfloor+K+\left\lfloor\frac{K}{4}\right\rfloor+\left\lfloor\frac{J}{4}\right\rfloor-2 J\right) \bmod 7,
$$

\begin{tabular}{|ccc|}
\hline $\mathbf{M}$ & $\mathbf{F ( M )}$ & My memory trick \\
\hline 1 & 1 & "1 and 3 pass through" \\
\hline 2 & 4 & 24 hours in a day \\
\hline 3 & 3 & "1 and 3 pass through" \\
\hline 4 & 6 & 4-6 are flips \\
\hline 5 & 7 & Heinz 57 sauce \\
\hline 6 & 4 & 6-4 are flips \\
\hline 7 & 6 & Spirit of 76 \\
\hline 8 & 2 & 8 is made up of 2s \\
\hline 9 & 5 & Working 9-to-5 \\
\hline 10 & 0 & Only \# with 0 .. is 0! \\
\hline 11 & 3 & 11 in Binary is 3 \\
\hline 12 & 5 & Working 12-5 (afternoons) \\
\hline & &
\end{tabular}




\section{Great Resource : CS4FN}

- Paul Curzon, Peter McOwan, Jonathan Black @ Queen Mary, University of London

- CS4FN magazine

- Two free books on Magic and CS!

- Some online apps

- If you'd like to contribute tricks, contact them...

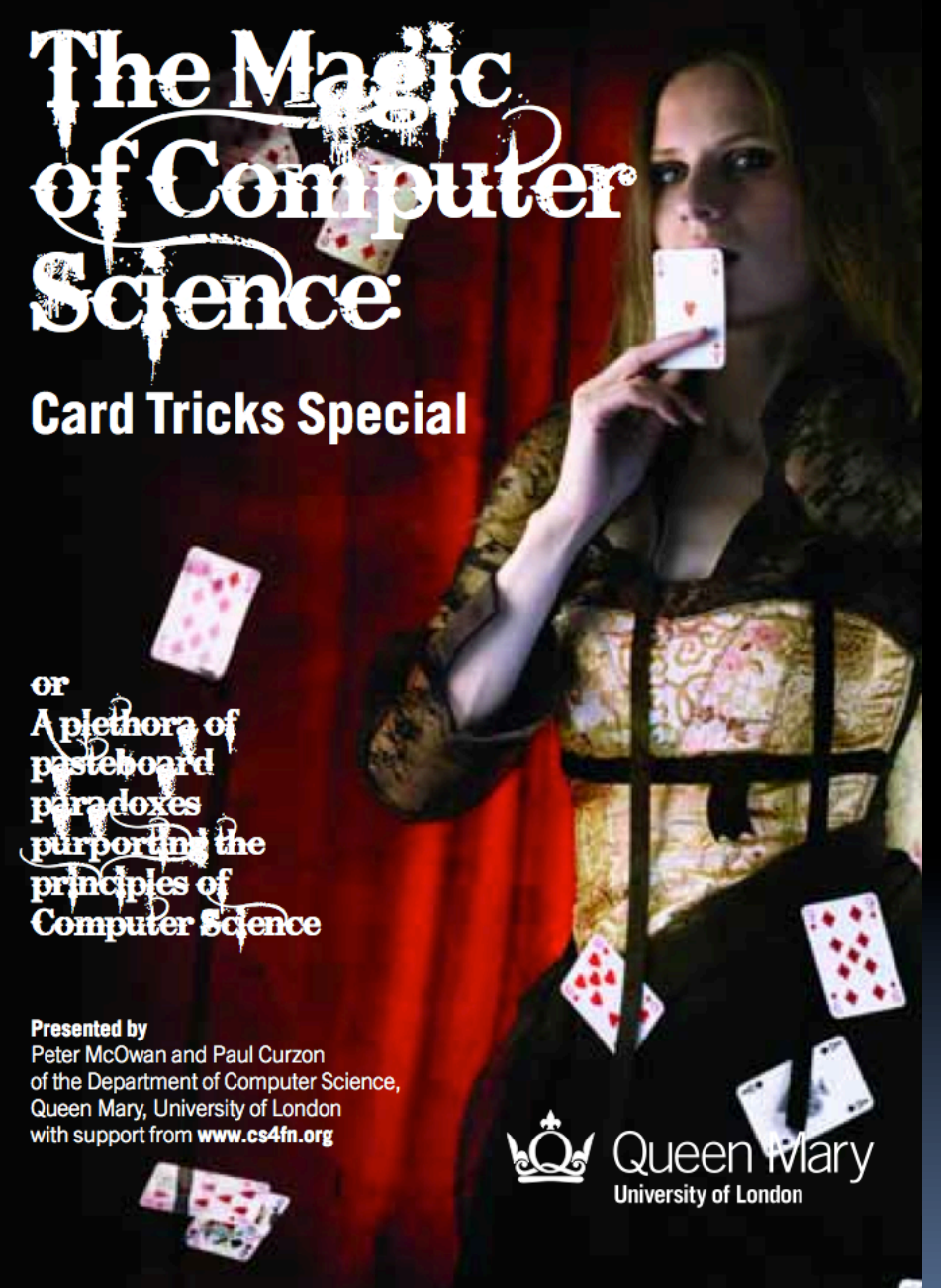




\section{Great Resource : Math Magic}

www.parents-choice.org/product.cfm?product_id=29300

- Kids Labs, $\$ 12$

- They include dice, cards, calculator, templates, ...

- Some of our tricks we demonstrated today were from this great resource!

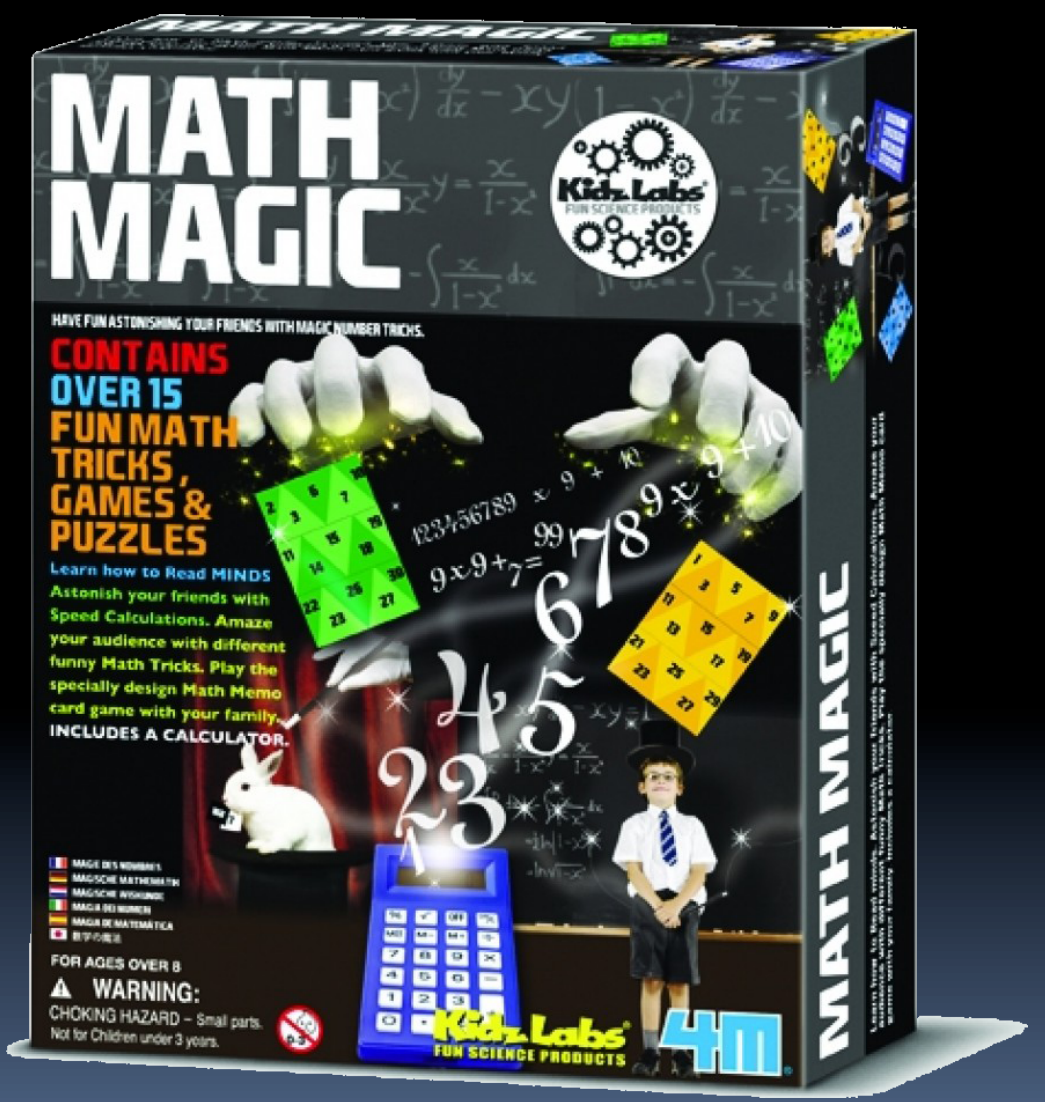




\section{AND IN CONCLUSION... MAGIC MAY BE USED TO}

Motivate, Illustrate, and Elaborate on:

- Computing notions

- Problem solving

- Divergent Thinking

Audience Participation Do YOU have any magic to share? 